\title{
Orhidejski hibridi (Orchidaceae) na otoku Krku
}

\author{
LJILJANA BOROVEČKI-VOSKA ${ }^{1 *}$, BERISLAV HORVATIĆ ${ }^{2}$ \\ ${ }^{1}$ Šubićeva 3, HR-10000 Zagreb, Hrvatska \\ ${ }^{2}$ Institut za fiziku, Bijenička cesta 46, HR-10000 Zagreb, Hrvatska
}

*Autor za dopisivanje / corresponding author: orchidlily.bor@gmail.com

Tip članka / article type: kratko stručno priopćenje / short professional communication

Povijest članka / article history: primljeno / received: 30.7.2020., prihvaćeno / accepted: 17.10.2020.

URL: https://doi.org/10.46232/glashbod.8.2.2

Borovečki-Voska, Lj., Horvatić, B. (2020): Orhidejski hibridi (Orchidaceae) na otoku Krku. Glas. Hrvat. bot. druš. 8(2): 78-87.

\section{Sažetak}

U sklopu sustavnog istraživanja porodice Orchidaceae na otoku Krku tijekom vegetacijskih sezona 2018 ., 2019. i 2020. zabilježeno je šest hibridnih svojti, dvije intergeneričke i četiri intrageneričke. Od toga je samo Orchis $\times$ gennarii Rchb. f. već uvrštena u bazu podataka Flora Croatica. Za pet od šest otkrivenih hibrida postoje literaturni podaci koji govore da su već ranije zabilježeni u Hrvatskoj, dok za intergenerički hibrid $\times$ Serapicamptis fontanae (E. G. Camus) H. Kretzschmar, Eccarius \& H. Dietr. nisu nađeni objavljeni podaci za Hrvatsku, pa taj nalaz možemo smatrati prvim.

Ključne riječi: hibridi, Krk, Kvarner, Mediteran, Orchidaceae

Borovečki-Voska, Lj., Horvatić, B. (2020): Orchid hybrids (Orchidaceae) on the island of Krk. Glas. Hrvat. bot. druš. 8(2): 78-87.

\section{Abstract}

Within the course of the systematic study of the Orchidaceae family on the island of Krk during the growing seasons of 2018, 2019, and 2020, six hybrid taxa were recorded, out of which two intergeneric and four intrageneric ones. Out of these, only Orchis $\times$ gennarii Rchb. f. has already been included in the Flora Croatica Database, although previous literature records for Croatia exist for five out of six discovered hybrids. No previous literature record was found for the intergeneric hybrid $\times$ Serapicamptis fontanae (E.G.Camus) H. Kretzschmar, Eccarius \& H. Dietr., therefore this finding can be considered its first record in Croatia.

Keywords: hybrids, Krk, Kvarner, Mediterranean, Orchidaceae 


\section{Uvod}

U bazi podataka Flora Croatica (u nastavku teksta FCD, Nikolić 2005-nadalje) trenutno su navedene 184 svojte porodice Orchidaceae. Od toga je 17 hibridnih, sve redom intrageneričkih, najviše unutar roda Ophrys (8), zatim Orchis (6) i Serapias (3). Najveći broj hibrida unutar roda kokice (Ophrys) može se objasniti činjenicom da na istim staništima često dolazi više različitih svojti toga roda čija se cvatnja vremenski preklapa te pojedine vrste dijele iste oprašivače koji, privučeni kemijskim mamcima, obavljaju na cvjetovima pseudokopulaciju, a pritom i oprašivanje. Ovome valja pridodati i veliku morfološku sličnost pojedinih svojti i ponekad veliku brojnost jedinki na staništu, kao i činjenicu da je upravo taj rod u našoj nacionalnoj flori unutar porodice Orchidaceae zastupljen najvećim brojem vrsta i podvrsta. No usprkos navedenim činjenicama hibridne jedinke su i unutar tog roda relativno rijetka pojava, prvenstveno zbog dobro razvijenih, uglavnom predzigotičkih mehanizama reproduktivne izolacije koji sprečavaju oprašivanje između različitih svojti. Kod kokica se to povezuje prvenstveno s visokospecifičnim oprašivačima. Naime, često i morfološki vrlo slične vrste izlučuju različite (pseudo)feromone pa stoga imaju i različite oprašivače, čime se sprečava slobodan protok gena između različitih svojti. Poznati su primjeri da različite svojte kokica ponekad imaju iste vrste oprašivača, ali da se čak i u tom slučaju postiže reproduktivna izolacija pričvršćivanjem polinija na različite dijelove kukčeva tijela. Kod orhideja koje su razvile takav visokospecifičan odnos s oprašivačima postzigotički izolacijski mehanizmi u pravilu su vrlo slabi ili nikakvi, što se uvelike koristi pri uzgoju hibrida u hortikulturi postupkom umjetnog oprašivanja kako bi se dobilo sjeme iz kojeg posebnim tretmanima asimbiotski klijaju mlade biljke. No kod onih vrsta koje kukcima nude, odnosno lažno nude hranu, pa imaju širi spektar manje specifičnih oprašivača, postzigotička reproduktivna izolacija je jača (Cozzolino i sur. 2005, Seaton i Ramsay 2005, Moccia i sur. 2007, Cozzolino i Scopece 2008, Zhang i Gao 2017). Naime, česta je pojava invijabilnost hibridnih zigota, a sve ako se i razviju, hibridne jedinke odlikuje slabi „fitness" ili pak su sterilne. Intergenerički hibridi su zbog još jačih reproduktivnih barijera vrlo rijetki. Naime, njihova hibridizacija ometena je nizom mehanizama reproduktivne izolacije: ekološkim, vremenskim, mehaničkim, nemogućnošću sparivanja gameta zbog različitog broja kromosoma ili pak općenito značajne razlike genetskih komplemenata dviju svojti, što rezultira nemogućnošću formiranja embrija ili pak sterilnošću hibrida.

\section{Materijali i metode}

Lokaliteti na otoku Krku obiđeni su u sklopu sustavnog istraživanja porodice Orchidaceae tijekom proljeća 2018., 2019. i 2020. godine. Pomoću GPS uređaja određene su Gauss-Krüger koordinate svakog lokaliteta. Determinacija svojti obavljena je pomoću Delforge (2006), Pedersen i Faurhodt (2007) i Kühn i sur. (2019). Nomenklatura hibridnih svojti usklađena je prema bazi The Plant List (2020) i International Plant Names Index (2020). Radi olakšavanja usklađivanja, gdje god je bilo potrebno, uz validni naziv pojedine svojte unesen je i sinonim pod kojim je ista svojta navedena u FCD-u. Proučena je morfologija roditeljskih i hibridnih svojti te napravljena prateća fotodokumentacija. 
Tablica 1. Pregledni prikaz hibridnih svojti orhideja dosad otkrivenih na otoku Krku.

\begin{tabular}{|c|c|c|c|c|c|}
\hline $\begin{array}{l}\text { NAZIV HIBRIDNE } \\
\text { SVOJTE }\end{array}$ & $\begin{array}{l}\text { RODITELJSKE } \\
\text { SVOJTE }\end{array}$ & NALAZIŠTE & $\begin{array}{l}\text { Gauss-Krüger } \\
\text { KOORDINATE }\end{array}$ & $\begin{array}{l}\text { BROJ } \\
\text { JEDINKI }\end{array}$ & $\begin{array}{l}\text { DATUM } \\
\text { NALAZA }\end{array}$ \\
\hline $\begin{array}{l}\times \text { Serapicamptis } \\
\text { rousii }\end{array}$ & $\begin{array}{l}\text { Anacamptis laxiflora } \\
\text { Serapias vomeracea }\end{array}$ & $\begin{array}{l}\text { Njivice } \\
\text { (Jezero) }\end{array}$ & $\begin{array}{l}X: 5466745 \\
Y: 5003165\end{array}$ & $\begin{array}{l}1 \\
0\end{array}$ & $\begin{array}{l}12.5 .2018 . \\
11.5 .2019 . \\
2020 .\end{array}$ \\
\hline $\begin{array}{l}\times \text { Serapicamptis } \\
\text { fontanae }\end{array}$ & $\begin{array}{l}\text { Anacamptis morio } \\
\text { Serapias vomeracea }\end{array}$ & $\begin{array}{l}\text { Gostinjac } \\
\text { (Brestovica) }\end{array}$ & $\begin{array}{l}X: 5471460 \\
Y: 4996775\end{array}$ & 1 & 3.5.2020. \\
\hline & & & $\begin{array}{l}X: 5473505 \\
Y: 4998300\end{array}$ & 1 & 22.4.2019. \\
\hline $\begin{array}{l}\text { Anacamptis } \times \\
\text { gennarii }\end{array}$ & $\begin{array}{l}\text { Anacamptis morio } \\
\text { Anacamptis } \\
\text { papilionacea }\end{array}$ & Polje & $\begin{array}{l}X: 5473970 \\
Y: 4999325\end{array}$ & 5 & 3.5.2020. \\
\hline & & & $\begin{array}{l}X: 5473805 \\
Y: 4998620\end{array}$ & 8 & 4.5.2020. \\
\hline Anacamptis $\times$ & Anacamptis laxiflora & $\begin{array}{l}\text { Njivice } \\
\text { (Jezero) }\end{array}$ & $\begin{array}{l}X: 5466845 \\
Y: 5003160\end{array}$ & 4 & 11.5.2019. \\
\hline & Anacamptis morio & $\begin{array}{l}\text { Punat (lokva } \\
\text { Mišušalnica) }\end{array}$ & $\begin{array}{l}X: 5472735 \\
Y: 4990025\end{array}$ & 2 & 9.5.2020. \\
\hline $\begin{array}{l}\text { Ophrys } \times \\
\text { koseciorum }\end{array}$ & $\begin{array}{l}\text { Ophrys untchjii } \\
\text { Ophrys zinsmeisteri }\end{array}$ & $\begin{array}{l}\text { Uvala Sv. Juraj } \\
\text { (Punta Groša) }\end{array}$ & $\begin{array}{l}X: 5462835 \\
Y: 4987035\end{array}$ & $\begin{array}{l}1 \\
3\end{array}$ & $\begin{array}{l}\text { 25.5.2019. } \\
11.5 .2020 .\end{array}$ \\
\hline $\begin{array}{l}\text { Serapias } \times \\
\text { intermedia }\end{array}$ & $\begin{array}{l}\text { Serapias lingua } \\
\text { Serapias vomeracea }\end{array}$ & Sulinj & $\begin{array}{l}X: 5469710 \\
Y: 5003195\end{array}$ & $\begin{array}{l}3 \\
0\end{array}$ & $\begin{array}{l}24.5 .2019 . \\
2020 .\end{array}$ \\
\hline
\end{tabular}




\section{Rezultati i diskusija}

\section{Intergenerički hibridi}

$\times$ Serapicamptis rousii (Du Puy) J. M. H. Shaw, Orchid Rev. Suppl. 113 (1264): 20 (2005)

Roditeljske vrste: Anacamptis laxiflora (Lam.) R. M. Bateman, Pridgeon \& M. W. Chase (= Orchis laxiflora Lam. ssp. laxiflora) i Serapias vomeracea (Burm. f.) Briq.

Sinonimi: $\times$ Orchiserapias purpurea E. G. Camus, $\times$ Orchiserapias rousii (Du Puy) H. Baumann \& Künkele, $\times$ Paludorchiserapias rousii (Du Puy) P. Delforge, Serapias $\times$ dupuyana Rouy, Serapias $\times$ purpurea Doumenjou, Serapias $\times$ rousii Du Puy, Serapias $\times$ triloba Dupuy ex Noulet

Prvi opis ovog hibrida dao je 1846. godine Du Puy pod imenom $\times \times$ Orchiserapias triloba, a potom 1892. E. G. Camus pod imenima $\times \times$ Orchiser. purpurea, odnosno $\times \times$ Orchiser. adulterina (Camus 1892, Camus i Camus 1928). Prvi nalaz za Hrvatsku objavio je R. Kranjčev u časopisu Hrvatska vodoprivreda (Kranjčev 2005). Kranjčev u članku spominje veliko bogatstvo orhidoflore na vlažnijim travnjacima na području Soline i, premda ne nabraja pojedine svojte, na priloženoj fotografiji nedvojbeno se prepoznaje hibrid $\times$ Serapicamptis rousii. Autor specijalističke internetske stranice za orhideje European Orchids and their Hybrids (2020) navodi da je ovaj hibrid zabilježen u Francuskoj, Italiji, bivšoj Jugoslaviji i Grčkoj, no ne daje preciznije lokalitete. Samo jednu jedinku ovog hibrida zabilježili smo u svibnju 2018. godine na vlažnom pašnjaku na padini s podvirnom vodom uz Jezero kod Njivica. Valja naglasiti da je na navedenom lokalitetu uz mnoštvo jedinki roditeljskih vrsta zabilježeno ukupno čak 15 svojti orhideja, što ovaj lokalitet čini iznimno vrijednim. Hibridna jedinka je po svim morfološkim obilježjima intermedijarna u odnosu na roditeljske vrste (Sl. 1). Na istom mikrolokalitetu uočena je i 2019. godine, no nažalost ne i 2020., kada je zbog dugotrajne proljetne suše ukupan broj jedinki svih orhideja na tom lokalitetu bio puno manji nego inače.

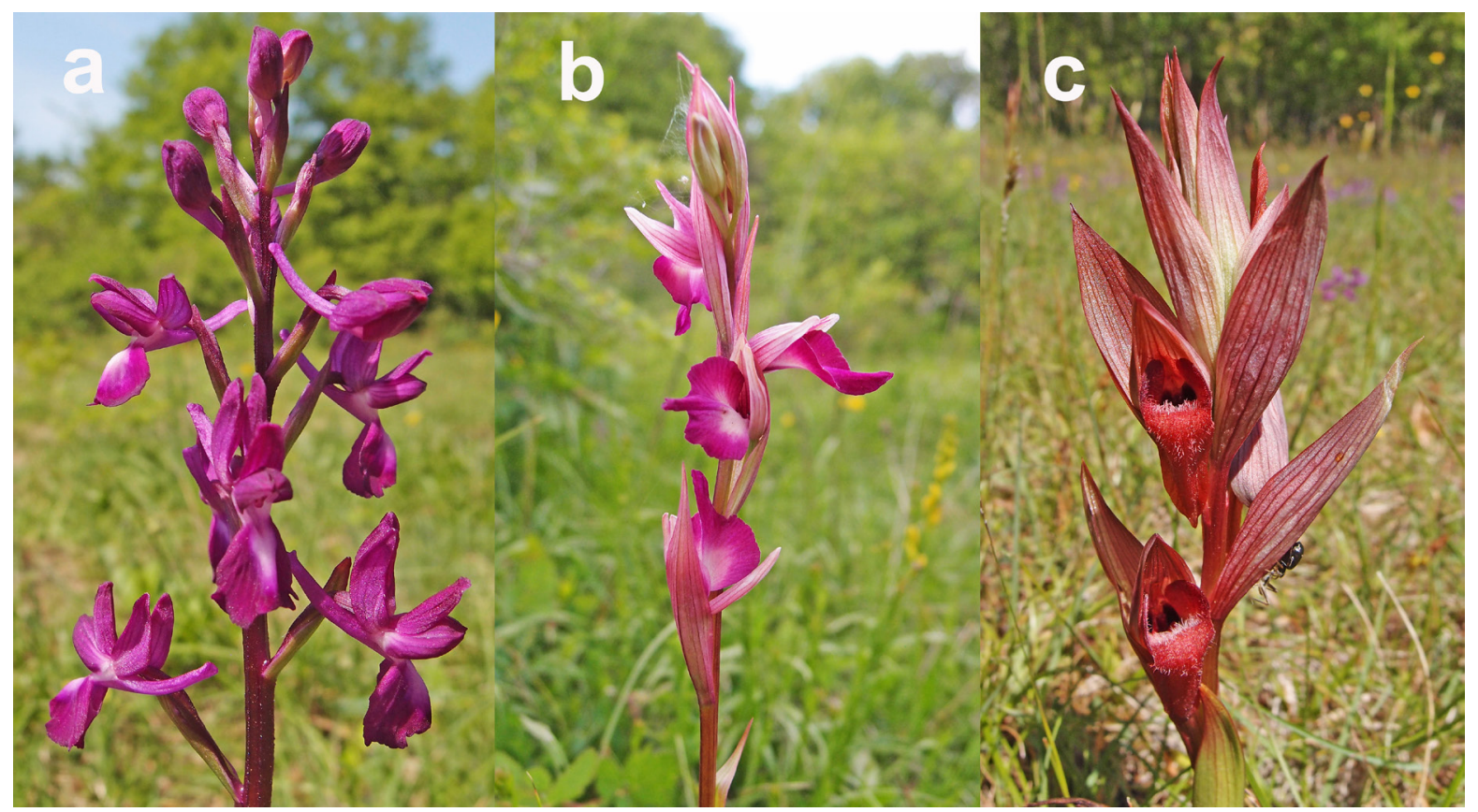

Slika 1. Hibrid $\times$ Serapicamptis rousii i roditeljske vrste: Anacamptis laxiflora (a), $\times$ Serapicamptis rousii (b) i Serapias vomeracea (c) (Foto: LJ. Borovečki-Voska, otok Krk, Jezero kod Njivica, 11. svibnja 2019.). 


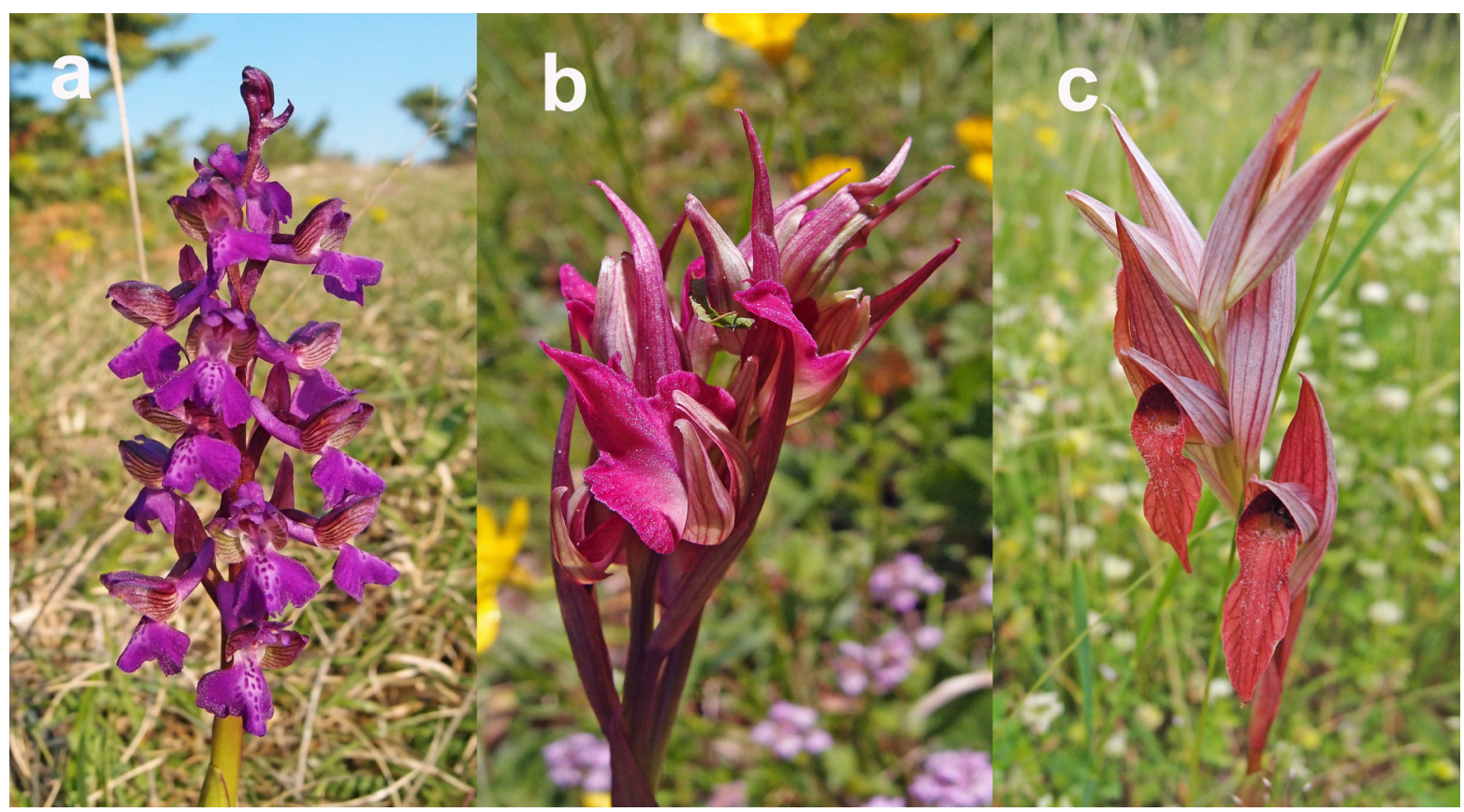

Slika 2. Hibrid $\times$ Serapicamptisfontanae i roditeljske vrste: Anacamptis morio (a), $\times$ Serapicamptisfontanae (b) i Serapias vomeracea (c) (Foto: B. Horvatić, otok Krk, Gostinjac (Brestovica), 3. svibnja 2020.).

$\times$ Serapicamptis fontanae (E. G. Camus) H. Kretzschmar, Eccarius \& H. Dietr., Orchid Gen. Anacamptis Orchis Neotinea 412 (2007)

Roditeljske vrste: Anacamptis morio (L.) R. M. Bateman, Pridgeon \& M. W. Chase (= Orchis morio L.) i Serapias vomeracea (Burm. f.) Briq.

Sinonimi: $\times$ Herorchiserapias fontanae (Rigo \& Goiran) P. Delforge, $\times$ Orchiserapias fontanae (Rigo \& Goiran) E. G. Camus, Serapias $\times$ fontanae Rigo \& Goiran

Prvi opis ovog hibrida dao je 1908. godine E. G. Camus pod imenom $\times \times$ Orchiserapias fontanae (Camus i sur. 1908), a za Hrvatsku dosad nema objavljenih nalaza. Ovaj hibrid pojavljuje se rjeđe od prethodnog jer se cvatnja roditeljskih vrsta jedva preklapa - kada Serapias vomeracea počinje cvasti, Anacamptis morio je s cvatnjom pri samom kraju, pa je stoga vjerojatnost hibridizacije značajno umanjena. U European Orchids and their Hybrids (2020) stoji da je zasad zabilježen samo u Francuskoj i Italiji, uključujući i Siciliju. Na mezofilnoj košanici kod Gostinjca početkom svibnja 2020. godine među mnoštvom jedinki roditeljskih vrsta uočena je jedna hibridna jedinka. Po obliku su cvjetovi hibrida intermedijarni, no svojom ružičastom bojom nešto više naginju prema A. morio (S1. 2).

\section{Intragenerički hibridi}

Anacamptis $\times$ gennarii (Rchb. f.) H. Kretzschmar, Eccarius \& H. Dietr., Orchid Gen. Anacamptis Orchis Neotinea ed. 2: 429 (2007)

Roditeljske vrste: Anacamptis morio (L.) R. M. Bateman, Pridgeon \& M. W. Chase (= Orchis morio L.) i Anacamptis papilionacea (L.) R. M. Bateman, Pridgeon \& M. W. Chase (= Orchis papilionacea L.)

Sinonimi: $\times$ Heromeulenia gennarii (Rchb. f.) P. Delforge, Orchis $\times$ gennarii Rchb. $f$.

Prvi opis datira iz 1850. godine (Reichenbach 1850), a najstariji nalaz tog hibrida u Hrvatskoj seže u 2002. godinu kada ga grupa autora spominje za Istru i kvarnerske otoke (Kerschbaumsteiner i sur. 2002). 


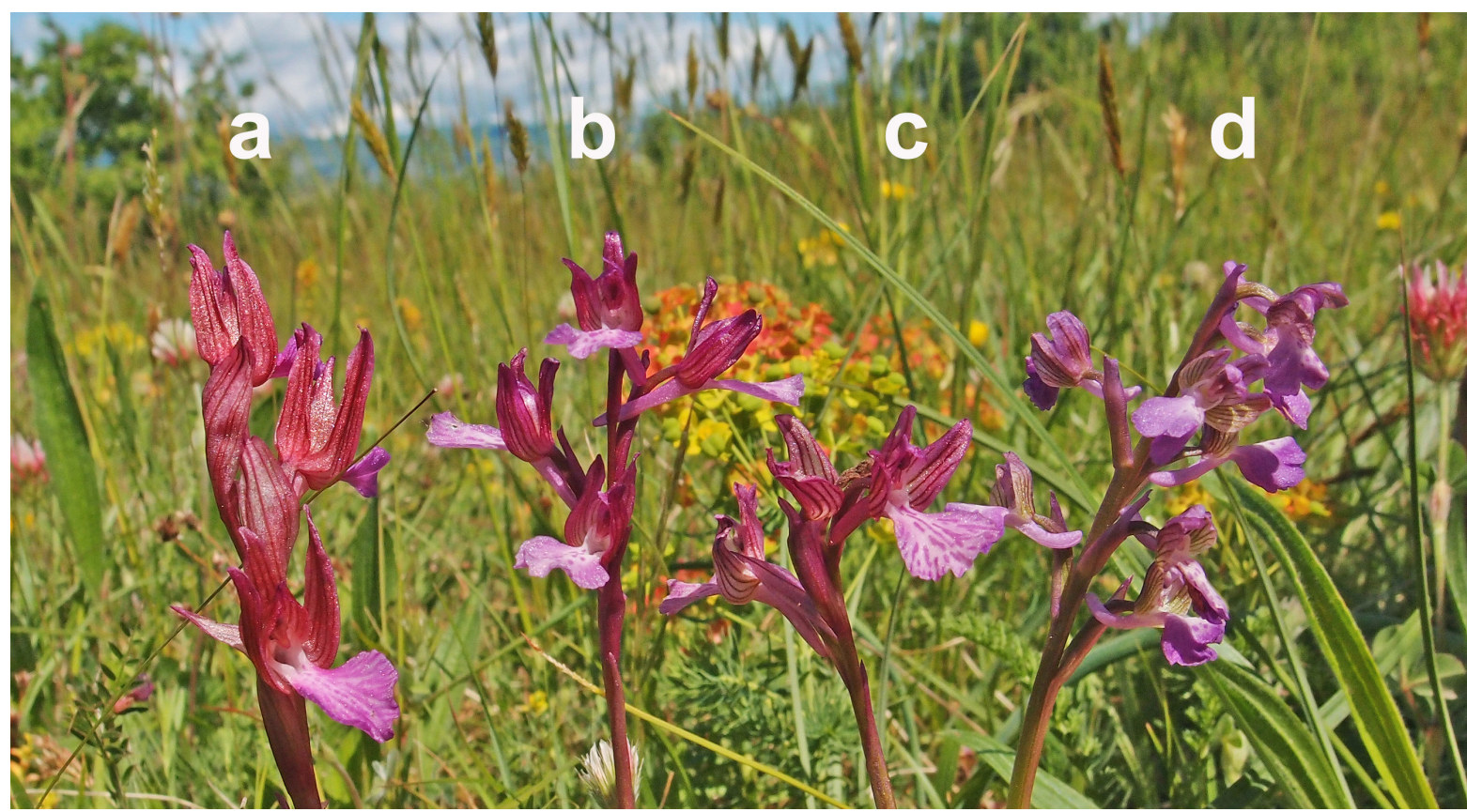

Slika 3. Hibrid Anacamptis $\times$ gennarii i roditeljske vrste: $A$. papilionacea (a), A. $\times$ gennarii (b i c), A. morio (d) (Foto: B. Horvatić, otok Krk, Polje, 3. svibnja 2020.).

Na rtu Donji Kamenjak bilježi ga 2007. godine S. Brana (Brana 2007), a dvije godine kasnije u svom radu isti hibrid na petnaestak lokaliteta u Istri navodi i N. Griebl (Griebl 2009). Na lokalitetima Donji, odnosno Gornji Kamenjak svojta je potvrđena i u radovima novijeg datuma (Vuković i sur. 2012, Bogdanović i sur. 2018).

Na temelju iskustva stečenog terenskim istraživanjima, izvjesno je da su mehanizmi reproduktivne izolacije između vrsta Anacamptis morio i A. papilionacea relativno slabi jer se na svim lokalitetima gdje se ove dvije vrste pojavljuju s većim brojem jedinki u pravilu pojavljuju i njihovi hibridi. $\mathrm{Na}$ otoku Krku zasad su zabilježena tri takva lokaliteta kako je navedeno u Tablici 1, u dvama maslinicima te na jednoj mezofilnoj košanici u Polju nedaleko Šila. Kada je na istom lokalitetu nazočan veći broj hibridnih jedinki, uočljivo je kako im habitus varira od potpuno intermedijarnih pa do onih koje više naginju jednom odnosno drugom roditelju, iz čega se može zaključiti da se radi o povratnom križanju, tj. introgresiji (Sl. 3). Valja naglasiti da je u jednom masliniku u Polju uz A. × gennarii zabilježeno još 11 drugih svojti orhideja s velikom brojnošću i gustoćom jedinki, što taj lokalitet čini botanički vrlo vrijednim.

Anacamptis $\times$ alata (Fleury) H. Kretzschmar, Eccarius \& H. Dietr., Orchid Gen. Anacamptis Orchis Neotinea ed. 2: 429 (2007)

Roditeljske vrste: Anacamptis laxiflora (Lam.) R. M. Bateman, Pridgeon \& M. W. Chase (= Orchis laxiflora Lam. ssp. laxiflora) i Anacamptis morio (L.) R. M. Bateman, Pridgeon \& M. W. Chase (= Orchis morio L.)

Sinonimi: $\times$ Heropaludorchis alata (Fleury) P. Delforge, Orchis $\times$ alata Fleury, Orchis laxiflora var. alata (Fleury) Nyman

Prvi opis ovog hibrida pod imenom $\times$ Orchis alata dao je J. F. Fleury 1819. godine (Fleury 1819). Najstariji objavljeni nalaz za Hrvatsku je od Griebla iz 2009. godine (Griebl 2009). U svom radu Griebl je objavio fotografiju hibridne jedinke nađene u Boljunu (Istra). Prema podacima u Plants of the World online (2020) areal Anacamptis $\times$ alata proteže se od Britanskog otočja, preko Francuske, Švicarske i Italije, do država bivše Jugoslavije i 


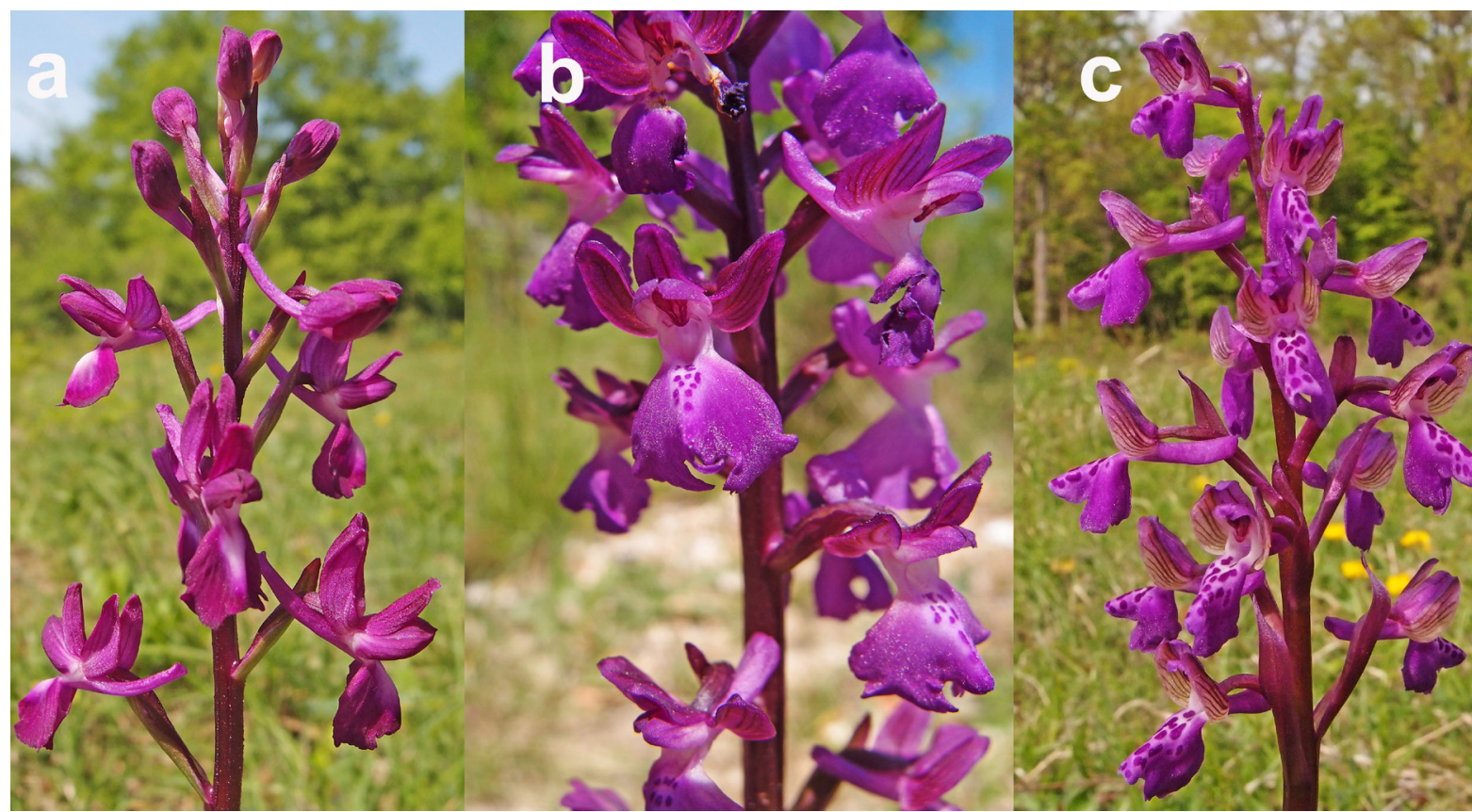

Slika 4. Hibrid Anacamptis $\times$ alata i roditeljske vrste: A. laxiflora (a), A. × alata (b) i A. morio (c) (Foto: B. Horvatić, otok Krk, Punat (lokva Mišušalnica), 9. svibnja 2020.).

Grčke. Ovaj intragenerički hibrid je relativno rijedak ponajviše zbog kratkog vremenskog preklapanja cvatnje roditeljskih vrsta. Na Krku je u sklopu ovog istraživanja zabilježen na vlažnim pašnjacima na dva lokaliteta - uz Jezero kod Njivica te uz lokvu Mišušalnicu nedaleko Punta (Tablica 1). Zbog prilične sličnosti roditeljskih vrsta i povratnog križanja, ovaj je hibrid nešto teže uočiti, a ponekad i razlučiti od roditeljskih jedinki. Hibridna jedinka na Sl. 4 je po obojenosti i obliku medne usne i ostruge intermedijarna u odnosu na roditeljske vrste. Također, i lateralni listići vanjskog kruga ocvijeća po obojenosti, odnosno ispruganosti te položaju u kojem stoje iznad ginostemija, pokazuju miješana svojstva roditeljskih vrsta. Kod A. morio ti su listići u pravilu stisnuti sa središnjim listićem vanjskog $\mathrm{i}$ dva listića unutarnjeg kruga u kacigu iznad ginostemija, dok su kod A. laxiflora previnuti unazad pod kutem od oko $90^{\circ}$ u odnosu na lateralne listiće. Kod hibridne jedinke pak sva tri listića vanjskog kruga ocvijeća leže razmaknuto u gotovo istoj ravnini.

Ophrys $\times$ koseciorum Čičmir, Naturalistes Belges 97(Orchid. 29): 52 (2016)
Roditeljske vrste: Ophrys untchjii (M.Schulze) P. Delforge i Ophrys zinsmeisteri A. Fuchs (= Ophrys kvarneri Perko et Kerschb.)

Hibrid Ophrys $\times$ koseciorum opisan je tek 2016 . godine (Čičmir 2016) i to upravo s otoka Krka (Glavotok). U opisu hibridnih jedinki s Glavotoka autor kao značajno svojstvo navodi intermedijarnu zelenoružičastu boju listića vanjskog kruga ocvijeća kao rezultat križanja roditeljskih jedinki od kojih jedna ima magenta (O. zinsmeisteri), a druga zeleno (O. untchjii) ocvijeće. S obzirom da je unutar pojedinih populacija i subpopulacija vrste $O$. untchjii u većini slučajeva udio jedinki sa zelenim listićima vanjskog kruga najveći, i vjerojatnost nastanka tako obojenih hibrida je najveća. U maslinicima iznad uvale Sv. Juraj, uz velik broj jedinki roditeljskih vrsta, 2019. i 2020. godine zabilježeno je nekoliko jedinki $O . \times$ koseciorum. $S$ obzirom da na tom lokalitetu u populaciji $O$. untchjii neuobičajeno velik broj jedinki ima bijele, odnosno svijetloružičaste listiće vanjskog kruga ocvijeća, ne iznenađuje da ondje pronađeni hibridni primjerci imaju intermedijarnu ružičastu, a ne zelenoružičastu boju vanjskih listića (Sl. 5). 


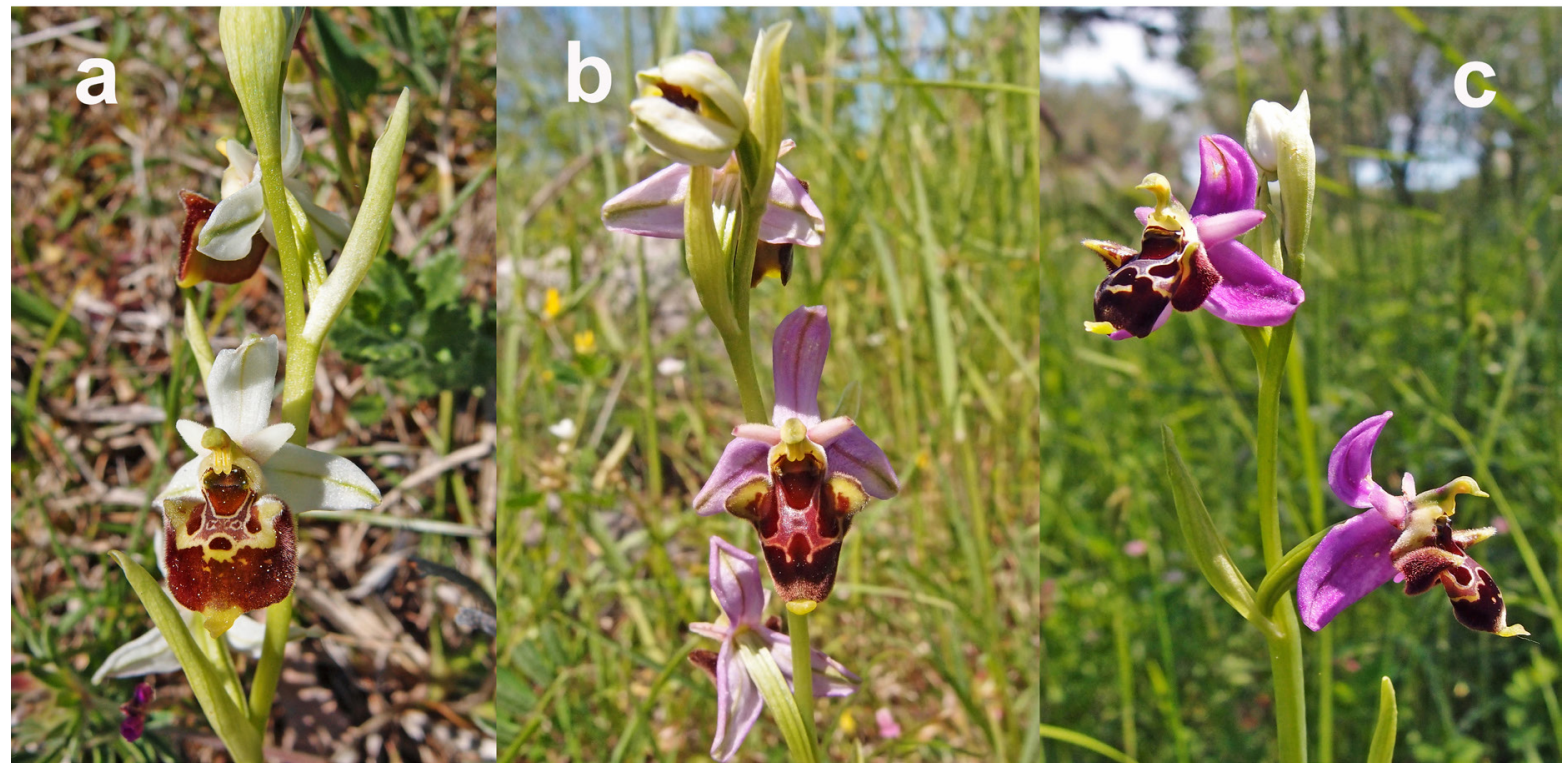

Slika 5. Hibrid Ophrys $\times$ koseciorum i roditeljske vrste: O. untchjii (a), $O . \times$ koseciorum (b) i O. zinsmeisteri (c) (Foto: B. Horvatić, otok Krk, uvala Sv. Juraj, 25. svibnja 2019.).

Serapias $\times$ intermedia Forest. ex F. W. Schultz, Arch. Fl. France Allemagne 1: 265 (1851)

Roditeljske vrste: Serapias lingua L. i Serapias vomeracea (Burm. f.) Briq.

Sinonimi: Serapias $\times$ digenea E. G. Camus, Serapias $\times$ forestieri Rouy, Serapias $\times$ grenieri K. Richt., Serapias $\times$ intermedia subsp. hyblaea Cristaudo, Galesi \& R. Lorenz, Serapias $\times$ philippii Rouy, Serapias $\times$ semicolumnae E. G. Camus \& A. Camus, Serapias $\times$ sitiae Renz

Prvi opis ovog hibrida datira iz 1851. godine (de Forestier 1851), a najstariji nalaz za Hrvatsku je od Kerschbaumsteiner i sur. (2002), a potom i od Griebla iz 2009 (Griebl 2009). Areal te svojte rasprostire se od Francuske i Italije (uključujući otoke Korziku i Siciliju) preko Hrvatske i Grčke (uključujući Kretu) pa do druge strane Sredozemnog mora na obalama Libije (Plants of the World online 2020). Na otoku Krku na rtu Sulinj, koji sa sjevera zatvara zaljev Soline, na dodirnoj liniji između zaravnjenja na kojem je nešto vlažniji i padine na kojoj je polusuhi pašnjak, susreću se populacije $S$. vomeracea i S. lingua. Na tom lokalitetu 2019. godine zabilježene su tri hibridne jedinke $S$. $\times$ intermedia (S1. 6). U svibnju 2020. godine nalaz nije potvrđen jer je zbog dugotrajne proljetne suše cvatnja orhideja bila izrazito siromašna.

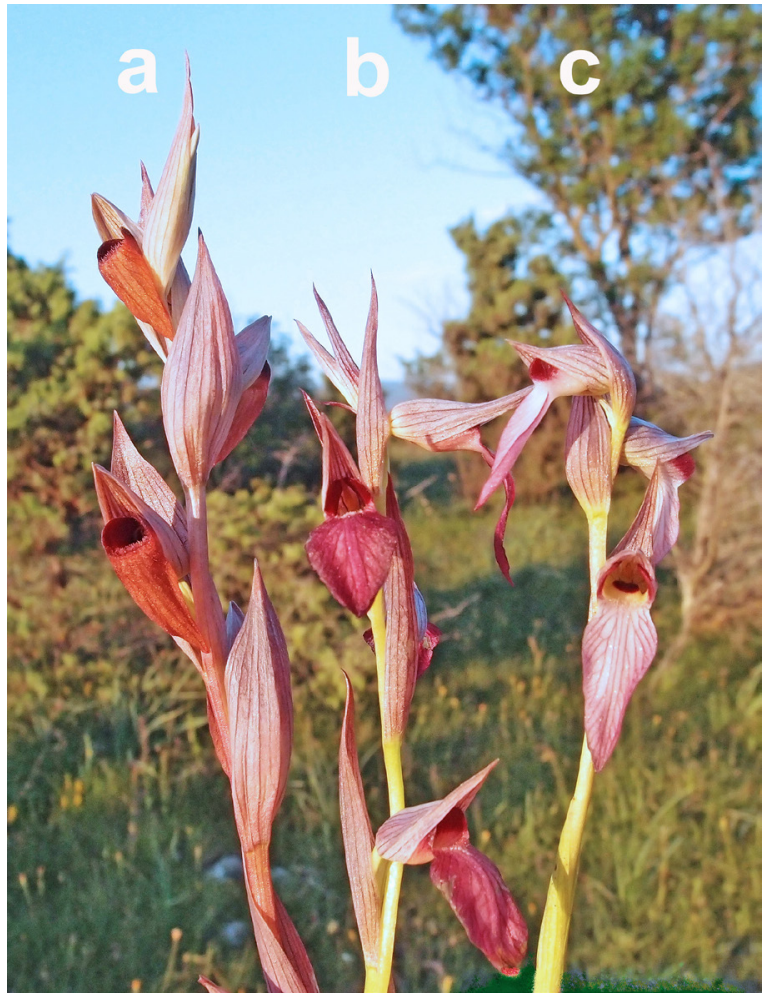

Slika 6. Hibrid Serapias $\times$ intermedia i roditeljske vrste: S. vomeracea (a), S. × intermedia (b) i S. lingua (c) (Foto: B. Horvatić, otok Krk, rt Sulinj, 24. svibnja 2019.). 


\section{Zaključak}

Tijekom istraživanja orhidoflore otoka Krka u tri uzastopne sezone (2018., 2019. i 2020. godine) zabilježeno je šest hibridnih svojti. Njihovi nalazi doprinose boljem poznavanju flore otoka Krka i Hrvatske, a istraživače i ljubitelje prirode potiču na pažljivije motrenje biljaka, jer su hibridne svojte rijetke, a njihove jedinke ponekad je teško uočiti pa i odrediti. Pet od šest svojti razmatranih u ovome radu valja uvrstiti u bazu podataka Flora Croatica (sve osim Anacamptis $\times$ gennarii koja je već uvedena pod imenom Orchis $\times$ gennarii Rchb. f.). Vrijedi istaknuti da je sustavnim istraživanjem kaćunovki, tj. orhideja (Orchidaceae) na Krku otkriveno nekoliko lokaliteta koji se ističu velikom brojnošću različitih svojti orhideja kao i velikom brojnošću jedinki, a na pojedinim lokalitetima zabilježene su i neke druge značajne vrste, npr. Cicendia filiformis (L.) Delarbre (kategorija DD na Crvenoj listi), Juncus capitatus Weigel (također kategorija DD) i Ophioglossum lusitanicum L. (kategorija CR) na rtu Sulinj, Ranunculus lingua L. (kategorija EN) uz Jezero kod Njivica, Carex extensa Gooden. (kategorija EN) u uvali Petrina te Saccharum ravennae (L.) Murray (kategorija CR) na rtovima Sulinj i Sv. Marak te u uvali Petrina. Stoga bi trebalo, u što skorijoj budućnosti, uspostaviti odgovarajuće mjere koje bi osigurale trajno povoljno stanje očuvanosti tih staništa.

\section{Zahvala}

Zahvaljujemo uredniku Sandru Bogdanoviću i dvojici recenzenata na primjedbama i sugestijama koje su doprinijele poboljšanju kvalitete ovog rada.

\section{Literatura}

Bogdanović, S., Iveša, N., Temunović, M. i Ljubičić, I. (2018): Plant Diversity of Gornji Kamenjak (Istria, Croatia). Agriculturae Conspectus Scientificus 83(3): 195-204.

Brana, S. (2007): Prijedlog za proglašenje dijela Značajnog krajobraza Donji Kamenjak i medulinski arhipelag, posebnim botaničkim rezervatom flore. 1-45.
Camus, E.G. (1892): Monographie des Orchidées de France. Journal de Botanique by Louis Morot 6: 31-32.

Camus, E.G., Camus, A. (1928): Iconographie des Orchidees d'Europe et du bassin Mediterraneen. P. Lechavalier, Paris.

Camus, E.G., Camus, A., P. Bergon, P. (1908): Monographie des Orchidées de 1'Europe, de 1'Afrique septentrionale, de l'Asie Mineure et des provinces russes transcaspiennes. París.

Cozzolino, S., Schiestl, F., Müller, A., De Castro, O., Nardella, A.-M., Widmer, A. (2005): Evidence for pollinator sharing in Mediterranean nectar-mimic orchids: absence of premating barriers? Biological Sciences 272(1569): 1271-1278.

Cozzolino, S., Scopece, G. (2008): Specificity in pollination and consequences for postmating reproductive isolation in deceptive Mediterranean orchids. Philosophical Transactions of the Royal Society B 363: 3037-3046.

Čičmir, R. (2016): Ophrys $\times$ koseciorum, nothosp. nat. nova. Naturalistes Belges 97(Orchid. 29): 49-54.

Delforge, P. (2006): Orchids of Europe, North Africa and the Middle East. A\&C Black Publishers Ltd., London.

European Orchids and their Hybrids (2020): http:// www.guenther-blaich.de/index.htm (pristupljeno 7. srpnja 2020.).

Fleury, J.F. (1819): Orchidées des environs de Rennes. Cousin-Danelle, Rennes, 32 pp.:17.

Forestier, de A. (1851): Archives de la Flore de France et d'Allemagne 265.

Griebl, N. (2009): Die Orchideen Istriens und deren Begleitflora Berichte aus den arbeitskreisen heimische orchideen. Ber. Arbeitskrs. Heim. Orchid. 26(2): 98-165.

International Plant Names Index (2020): https:// www.ipni.org/ (pristupljeno 7. srpnja 2020.).

Kerschaumsteiner, H., Perko, M.L., Stimpfl, G. (2002): Die Orchideen Istriens und der Kvarner Inseln Krk, Cres und Losinj - ein Vorbericht der Arbeitsgruppe. Jour. Europ. Orchid. 34 (1): 115-127. KewScience - Plants of the World online (2020): http://powo.science.kew.org/ (pristupljeno 23. srpnja 2020.). 
Kranjčev, R. (2005): Krčke vode i vodice. Hrvatska vodoprivreda 14(145): 21-25.

Kühn, R., Pedersen, H.Æ., Cribb, Ph. (2019): Field Guide to the Orchids of Europe and the Mediterranean. Royal Botanic Gardens, Kew.

Moccia, M.-D., WIdmer, A., Cozzolino, S. (2007): The strength of reproductive isolation in two hybridizing food-deceptive orchid species. Molecular Ecology 16(14): 2855-2866.

Nikolić, T. (ur.) (2020): Flora Croatica Database. Sveučilište u Zagrebu, Prirodoslovno-matematički fakultet, Botanički zavod, Zagreb. http://hirc. botanic.hr/fcd (pristupljeno 26. srpnja 2020.).

Pedersen, H.Æ., Faurhodt, N. (2007): Ophrys: The Bee Orchids of Europe. Royal Botanic Gardens, Kew.
Reichenbach, H.G.L. (1850): Icones florae Germanicae et Helveticae, simul Pedemontanae, Tirolensis, Istriacae, Dalmaticae, Austriacae, Hungaricae, Transylvanicae, Moravicae, Borussicae, Holsaticae, Belgicae, Hollandicae, ergo Mediae Europae. Iconographia et supplementum ad opera Willdenowii [et al.] ... 13/14: 172., F. Hofmeister [etc.] 1834-1912., Leipzig.

Seaton, Ph., Ramsay, M. (2005): Growing Orchids from Seed. Royal Botanic Gardens, Kew.

The Plant List (2020): http://www.theplantlist.org/ (pristupljeno 7. srpnja 2020.).

Vuković, N., Brana, S., Mitić, B. (2011): Orchid diversity of the cape of Kamenjak (Istria, Croatia). Acta Botanica Croatica 70(1): 23-40.

Zhang, W., Gao, J. (2017): Multiple factors contribute to reproductive isolation between two co-existing Habenaria species (Orchidaceae). PLoS One 12(11): e0188594. 